
internationales

vol. 21 - n³ | 2005

Familles, destins personnels et appartenances collectives en migration

\title{
« ¿Bienvenidos a Miami? »
}

La politique cubaine américaine de 1959 à 2004

Jean-Michel Lafleur

\section{(2) OpenEdition}

\section{Journals}

Édition électronique

URL : https://journals.openedition.org/remi/2527

DOI : 10.4000/remi.2527

ISSN : $1777-5418$

Éditeur

Université de Poitiers

Édition imprimée

Date de publication : 1 décembre 2005

Pagination : 149-177

ISBN : 2-911627-45-8

ISSN : 0765-0752

Référence électronique

Jean-Michel Lafleur, « « ¿Bienvenidos a Miami? » », Revue européenne des migrations internationales [En ligne], vol. 21 - n³ | 2005, mis en ligne le 01 décembre 2008, consulté le 15 avril 2022. URL : http:// journals.openedition.org/remi/2527 ; DOI : https://doi.org/10.4000/remi.2527

Ce document a été généré automatiquement le 15 avril 2022.

() Université de Poitiers 


\title{
« ¿Bienvenidos a Miami?»
}

\author{
La politique cubaine américaine de 1959 à 2004
}

\author{
Jean-Michel Lafleur
}

Le 2 novembre 2004, l'attention des médias s'est portée sur la péninsule floridienne où l'on attendait que soit désigné le nouvel occupant de la Maison Blanche ${ }^{1}$. Le suspense annoncé par beaucoup n'a toutefois pas duré. La victoire aisée du candidat Bush ferait presque oublier la querelle ayant opposé républicains et démocrates quatre ans plus tôt dans ce même État. Au-delà des lacunes techniques, c'est le fonctionnement démocratique en Floride qui est mis en cause après l'élection de 2000. Le rôle du pouvoir judiciaire et de certaines figures politiques est alors épinglé. À ce moment, on comprend également l'importance de la communauté cubaine américaine ${ }^{2}$ sur la scène politique floridienne.

2 Pourtant, cette communauté est politiquement active aux États-Unis depuis une quarantaine d'années déjà. Selon les époques, ses activités ont été légales ou non. À certains moments, elles prennent pour cible unique le régime de Fidel Castro, à d'autres, elles visent le monde politique étasunien. Qu'il s'agisse d'activisme ou plus tard de lobbying, la lutte contre le Líder Máximo est toutefois une constante depuis l'arrivée des premiers migrants en Floride. Cette affirmation est remise en question au tournant du XxI ${ }^{e}$ siècle lorsque le consensus conservateur parmi les Cubains de Miami montre ses premiers signes de faiblesse. Cet article cherche à replacer cette crise apparente dans le contexte général du changement de statut de la communauté. Dans cette perspective, nous posons l'hypothèse du passage d'une communauté d'exilés à une communauté ayant des pratiques transnationales.

3 Pour soutenir cette hypothèse, l'analyse débute aux origines de la migration cubaine vers les États-Unis. Après un bref rappel des liens unissant la Floride et Cuba, les principales étapes des migrations cubaines vers la péninsule sont passées en revue. Cet exercice révèle les différences opposant les migrants cubains arrivés avant 1980 et les autres. Les raisons ayant conduit à la formation de l'enclave cubaine au sud de la Floride sont ensuite examinées. Une fois les acteurs identifiés et l'espace socioéconomique déterminé, l'analyse portera sur les activités politiques de la communauté cubaine américaine. On distingue trois grandes étapes (1959-1980, 
1980-1989, 1989 à nos jours). Un accent tout particulier est mis sur la période allant des années 1990 à nos jours. Les dissensions qui se produisent à notre époque supportent en effet l'hypothèse du changement de statut de la communauté. L'article se conclut sur l'identification des changements démographiques et la modification du comportement électoral, preuves de l'émergence de pratiques transnationales au sein de la communauté cubaine américaine au XxI ${ }^{\mathrm{e}}$ siècle.

\section{Le temps de la migration}

Bien avant que le sud de la Floride ne connaisse les migrations cubaines, son histoire était déjà liée à celle de Cuba. Dans les années 1890 , le leader révolutionnaire cubain José Marti prépare à Key West ${ }^{3}$ ses plans d'invasion de l'île contre le pouvoir colonial espagnol ${ }^{4}$. Après avoir défait les Espagnols, l'espoir des combattants cubains est déçu. Le protectorat américain instauré sur l'île ne ressemble guère à l'indépendance que les leaders cubains avaient imaginée.

5 Dès le début des années 1930, une petite communauté cubaine issue de la classe moyenne est présente à Miami. En 1933, le Général Machado est renversé et s'exile à Miami avec ses partisans (Mohl, 1985 : 55). Au terme d'une longue période d'instabilité politique, le général Batista prend le pouvoir par un coup d'État en 1952. L'opposition à son régime s'organise depuis Miami où Carlos Prió, le président démis, s'associe à Fidel Castro pour renverser Batista. C'est en 1956 que Fidel Castro prend le maquis à Cuba. Grâce à des fonds récoltés par l'opposition cubaine résidant aux États-Unis, il organise alors la révolution de 1959 qui conduira à la chute de Batista (Perez, 2003 : 192-194 et 233-237).

6 La première moitié $\mathrm{du} \mathrm{xx}^{\mathrm{e}}$ siècle est riche en retournements politiques pour la jeune nation cubaine. Tous ces événements ont cependant un point commun : la Floride est la base de repli des insurgés qui préparent l'invasion contre le pouvoir en place.

\section{L'exil}

7 C'est la révolution cubaine de 1959 qui marque le début de l'émigration cubaine vers les États-Unis. On peut ensuite isoler trois phases. Elles se distinguent par le statut socioéconomique des migrants et les raisons de leur départ (Pedraza-Bailey, 1985 : 9).

Les premiers Cubains à prendre la fuite pour Miami sont les dirigeants du régime de Batista. Suivent les membres de l'élite économique cubaine que la vague de nationalisation de 1960 menace. Environ 135000 Cubains arrivent à Miami durant cette phase d'immigration cubaine entre 1959 et 1961 (Portes et Stepick, 1993 : 102). Le profil de ces migrants cubains comporte quelques spécificités. D’abord, la raison de leur départ est essentiellement politique. Ces personnes sont poussées à la migration en raison des liens qu'ils ont avec le régime de Batista et leur refus du nouvel ordre social. Ensuite, ces migrants appartiennent majoritairement à l'élite cubaine prérévolutionnaire et jouissent d'une certaine aisance financière (contrairement aux migrants qui les suivront quelques décennies plus tard). Enfin, grâce à son pouvoir économique, une partie de cette élite cubaine connaît déjà Miami pour y avoir passé régulièrement des vacances. 
9 La seconde phase débute après l'épisode de la Baie des Cochons en 1961. Le rythme des départs s'accélère mais c'est désormais moins l'élite que la classe moyenne cubaine qui s'exile. Ces départs sont d'autant plus fréquents que les vols entre Miami et la Havane sont maintenus jusqu'à la crise de Cuba en 1962. L'administration Kennedy met sur pied en 1961 le Cuban Refugee Program destiné à aider les nouveaux arrivants ${ }^{5}$. Les flux migratoires, après la crise de 1962, se stabilisent aux alentours de 15000 personnes par an jusqu'en 1965, alors que, suite à l'embargo, les difficultés de quitter l'île se font sentir (Portes et Stepick, 1993 : 103).

10 Un renversement se produit en 1965 lorsque le gouvernement cubain décide d'ouvrir ses portes aux citoyens désireux de partir: cinq mille Cubains saisissent cette opportunité. Inquiétée par cet évènement, l'administration Johnson signe une convention avec le gouvernement cubain afin d'organiser un pont aérien entre Cuba et Miami jusqu'en 1973.

11 Les vingt premières années d'émigration cubaine vers les États-Unis sont essentiellement le fait d'une élite d'abord, et de la classe moyenne ensuite. Celle-ci se distingue de l'élite cubaine par sa vision du régime en place et par l'importance de ses ressources. Si les derniers arrivants considèrent le régime castriste comme bien installé, les premiers poursuivent l'idée de le renverser rapidement (Pedraza-Bailey, $1985: 11)$.

$12 \mathrm{Du}$ point de vue américain, l'immigration cubaine s'inscrit dans la lutte contre le communisme. Au même titre que les migrants d'Europe centrale et orientale, les exilés cubains sont considérés comme des réfugiés politiques et se voient accorder un statut préférentiel (Forment, 1998: 52). Les autorités américaines tentent également de disperser l'immigration cubaine sur leur territoire. Dans le cadre du Cuban Refugee Program, des aides sont accordées aux réfugiés qui choisissent de s'installer ailleurs qu'à Miami. Malgré ces mesures, $80 \%$ des immigrés cubains y résidaient en 1979 (Portes et Stepick, 1993 : 104).

13 La présidence Carter marque une détente dans les relations entre les États-Unis et Cuba. Durant cette période, Castro engage le dialogue avec la communauté cubaine américaine. On peut interpréter ce mouvement comme une tentative de rapprochement politique et économique de Cuba avec les États-Unis. Trois cents prisonniers politiques sont libérés entre 1978 et 1979 et 100000 exilés cubains retournent au pays pour visiter leurs proches (Pedraza-Bailey, 1985 : 21). Au total, ce ne sont pas moins de 680000 Cubains qui rejoignent les États-Unis entre janvier 1959 et mars 1980 (Portes et Mozo, 1985 : 37). Peu d'indices laissent présager qu'un mouvement migratoire massif soit sur le point de se produire.

14 Par ailleurs, le taux de naturalisation dans la communauté cubaine américaine à cette époque fait croire à son assimilation prochaine. On n'exclut donc pas que les Cubains américains cessent d'être une communauté d'exilés et deviennent un groupe ethnique (ibid., 39). On peut distinguer ces deux groupes par leurs rapports politiques avec le pays d'origine. La communauté d'exilés prétend agir directement dans son pays d'origine (en tentant de renverser le pouvoir en place) tandis que le groupe ethnique utilise les institutions du pays d'accueil pour provoquer une modification de la situation politique du pays d'origine (au moyen du lobbying ethnique). 


\section{L'épisode du Port de Mariel}

C'est un événement somme toute banal qui relance l'immigration cubaine et déclenche la troisième phase d'immigration vers la Floride. Le $1^{\text {er }}$ avril 1980 , un chauffeur d'autobus défonce la grille d'accès de l'Ambassade péruvienne à la Havane pour y demander l'asile politique. Un garde cubain succombe durant ces événements. Fidel Castro réagit en retirant la protection policière de l'ambassade. En conséquence, plus de dix mille Cubains se presseront aux portes de l'ambassade pour demander l'asile. Le signal envers le régime castriste est trop fort pour rester sans réaction. Le gouvernement déclare que tout individu qui souhaite quitter le pays peut le faire en se rendant au Port de Mariel.

Entre mai et septembre 1980, 124769 réfugiés cubains entrent sur le territoire américain. Ceci constitue la plus grande vague d'immigration cubaine (Portes et Mozo, 1985 : 38). À la différence de 1965, année durant laquelle Cuba avait déjà autorisé l'exil, ce sont les immigrés cubains déjà installés aux États-Unis qui organisent le transport des candidats au départ. Ils affrètent des bateaux depuis Miami à destination du Port de Mariel dans l'espoir de ramener leurs proches.

17 Cet épisode est novateur à plus d'un titre. D'abord, parce qu'il voit partir des personnes de leur plein gré et d'autres forcées par le gouvernement cubain. Parmi celles-ci, on retrouve une proportion d'«indésirables" aux yeux de Fidel Castro: délinquants, malades mentaux ou homosexuels ${ }^{6}$. Pour cette raison, les immigrés du Port de Mariel sont rapidement la cible des médias américains qui propagent l'idée que les nouveaux arrivants causent du tort à l'ensemble de la communauté cubaine américaine. Jusqu'alors, la communauté bénéficiait d'une image positive dans l'opinion publique en raison de son succès économique.

Cette nouvelle population se distingue également des exilés précédents par sa composition ethnique. $40 \%$ des réfugiés de Mariel sont d'origine africaine contre 6,5\% en 1960 et seulement 2,6\% en 1970 (Pedraza-Bailey, 1985 : 23). En outre, la moyenne d'âge de ces nouveaux réfugiés est sensiblement inférieure à celle des migrations antérieures (Portes, Stepick et Truelove, $1986: 85$ ).

Aux différences de couleur et d'âge s'ajoutent celles qui sont liées au statut socioéconomique. Entre 1959 et 1962, 64 \% des migrants occupaient des positions de managers, d'employés de bureau ou de vendeurs (cols blancs) avant leur départ pour les États-Unis. Au cours des années 1960 et 1970, la proportion de managers diminue fortement mais la population de travailleurs qualifiés, bien qu'en déclin constant, reste proche de $25 \%$ jusqu'en 1974. En 1980, la population de travailleurs qualifiés s'est maintenue, mais la proportion de cols blancs chute sensiblement (Pedraza-Bailey, $1985: 13)$.

En conclusion, l'image véhiculée par les médias et l'opinion publique, la composition ethnique, le statut socioéconomique et l'accueil réservé aux immigrés du Port de Mariel diminuent leurs chances de réussite économique et créent, en outre, une rupture dans l'histoire de l'immigration cubaine vers les États-Unis (Portes, Stepick et Truelove, $1986: 87)$. 


\section{La migration cubaine après l'épisode de Mariel}

21 Après l'épisode du Port de Mariel, la communauté cubaine américaine compte environ 800000 membres. Les mouvements migratoires postérieurs seront composés d'individus défavorisés dont les motivations sont plus économiques que politiques. Les exilés des années 1980 et 1990 ne connaissent, pour leur majorité, que le Cuba de Castro. Au contraire de leurs prédécesseurs, ils quittent l'île sans avoir l'espoir d'y retourner pour renverser le régime.

Les motivations économiques de la nouvelle migration cubaine en font un cas moins exceptionnel dans le paysage migratoire mondial. Néanmoins, l'immigration cubaine reste favorisée par rapport à d'autres. D'une part, la législation américaine accorde aux Cubains un droit de résidence permanent dès leur entrée sur le territoire et d'autre part ils jouissent d'avantages socioéconomiques liés à la formation de l'enclave cubaine à Miami.

Depuis 1994 et l'accord migratoire entre Cuba et les États-Unis, Washington réserve chaque année 20000 places aux immigrés cubains; seuls les immigrés ayant préalablement posé leur candidature sont acceptés ${ }^{7}$. Si l'administration Clinton semble ainsi fermer la porte à l'immigration cubaine non réglementée, elle lui laisse néanmoins une opportunité en instaurant la politique dite du «wet foot - dry foot». Cette politique prévoit que tout candidat à l'immigration clandestine, intercepté en mer sera renvoyé immédiatement à Cuba, à l'exception de celui qui peut justifier une demande d'asile. En revanche, les migrants qui parviennent à mettre le pied sur le sol américain sont de facto admissibles pour l'asile (Abraham, 2001 : 205 ; Heindl, $2003: 47$ ).

\section{La formation de l'enclave ou le miracle socioéconomique cubain américain}

24 À ce jour, la communauté cubaine américaine compte 1,2 million d'individus et représente la troisième population hispanique du pays. La moitié de la communauté est arrivée durant les années 1960. Le recensement américain de 2000 (Census 2000), comme les précédents, montre que dans de nombreux domaines, elle fait mieux que les autres communautés d'origine hispanique ${ }^{8}:$ les Cubains américains ont un plus grand nombre de diplômés universitaires, de meilleures situations professionnelles et des revenus plus élevés. Cependant, la communauté n'a pas encore atteint le niveau moyen américain (Boswell, 2002). En d'autres termes, si les Cubains se différencient des autres communautés immigrées par un statut socioéconomique plus élevé, ce dernier n'est pas encore à la hauteur de la population blanche anglo-saxonne des États-Unis. Enfin, la communauté cubaine américaine se distingue par sa tendance à privilégier les contacts économiques intra-communautaires (Wilson et Martin, 1982 :147-154).

\section{La concentration géographique}

Dès 1979 , près de $80 \%$ des Cubains résidant aux États-Unis sont installés à Miami. Malgré les primes à la dispersion, une enquête de 1973 révèle que $27 \%$ des immigrés cubains résidant à Miami ont habité préalablement dans une autre localité américaine ; la proportion monte à $40 \%$ dans une enquête de 1978 (Portes et Stepick, 1993 : 104). Aujourd'hui, la Floride accueille $67 \%$ de l'ensemble de la population cubaine 
américaine: $52 \%$ habite dans le seul comté de Miami-Dade selon le Bureau du recensement, ce qui représente $29 \%$ des 2,2 millions d'habitants du comté. En raison de la diversification de l'immigration latino-américaine dans la région de Miami, la communauté cubaine ne constitue plus aujourd'hui que $50 \%$ de la population hispanique du comté (Boswell, 2002). La seconde plus grande concentration cubaine aux États-Unis est la zone de New York - New Jersey - Long Island où résident $11 \%$ des Cubains américains.

\section{La formation de l'enclave}

On trouve dans la littérature trois types d'analyse qui expliquent l'existence de l'enclave cubaine dans le sud de la Floride. La première, défendue par Silvia PedrazaBailey (1985 : 4-34), met l'accent sur le contexte international. L'immigration cubaine entre 1959 et 1989 s'est déroulée dans un climat de guerre froide. Dès lors elle revêtait comme l'immigration est-européenne un caractère symbolique pour le gouvernement américain alors engagé dans la lutte contre le communisme. L'utilisation des mouvements migratoires comme symbole de l'échec de l'ennemi permet aux Cubains de bénéficier des faveurs d'un gouvernement américain soucieux de prouver la supériorité de son idéologie : 957 millions de dollars sont dépensés par Washington (Cuban Refugee Program) entre 1960 et 1975. Le capital financier associé au capital humain des immigrés issus de l'élite et de la classe moyenne aurait donc conduit à la formation de l'enclave. Cette explication, qui soutient l'idée de la réussite de la communauté cubaine, peine cependant à démontrer les raisons de la concentration géographique.

La seconde interprétation, défendue par Carlos Forment (1998: 50), se concentre sur le rôle de l'État. L'émergence de l'enclave serait liée à la volonté du gouvernement américain de contrôler l'évolution politique du bassin des Caraïbes. Pour cette raison, il installe à Miami un des plus grands centres de la CIA afin de recruter et de former des mouvements de guérillas ${ }^{9}$. Pour Forment, la collaboration entre la CIA et les exilés Cubains est déterminante dans la formation de l'enclave. Si cette argumentation donne des clés à la compréhension de la réussite socioéconomique et à la concentration géographique, elle n'en reste pas moins contestée par Alejandro Portes, l'une des références en matière d'immigration cubaine. Pour ce dernier, les salaires payés par la CIA aux exilés cubains et la présence d'entreprises cubaines à Miami servant d'écran aux activités de la CIA ne suffisent pas à expliquer l'émergence d'une économie ethnique et son maintien à travers le temps.

Portes et Stepick (1993 : 127) énoncent trois critères conditionnant l'émergence d'une économie ethnique: une économie de marché stable permettant aux immigrés de vendre des biens culturellement associés à la communauté, un accès à une maind'œuvre bon marché à l'intérieur de la communauté et enfin l'accès au capital.

Si la première condition semble aller de soi dans une ville des États-Unis, il n'en va pas de même pour les deux autres. Avant l'arrivée des Cubains, Miami n'était qu'une station de villégiature pour WASP fortunés ${ }^{10}$. Le tourisme était la principale ressource économique et les premiers immigrés cubains animés par l'idée de renverser Castro ne la considéraient que comme un lieu de résidence temporaire.

30 Ce n'est qu'à la suite de la crise des missiles de 1962 et le " pacte de non-agression » entre les États-Unis et Cuba que le pouvoir du Líder Máximo se consolide, réduisant les 
espoirs de retour des exilés cubains vers leur patrie. Dans ce contexte, les perspectives d'établissement durable des Cubains à Miami n'échappent pas au monde industriel et des entreprises, notamment dans le secteur du textile, délocalisent leurs activités à Miami pour bénéficier de la main-d'œuvre cubaine réputée bon marché et qualifiée.

Parallèlement, les petites banques détenues par du capital sud-américain engagent des banquiers cubains exilés à Miami. Se développe alors un système de prêts basé autant sur la capacité de remboursement de l'emprunteur que sur sa réputation lorsqu'il vivait à Cuba. Ce système permet à de nombreux exilés de monter leur entreprise tout en garantissant au banquier le remboursement des emprunts. Une défaillance du débiteur nuirait en effet à sa réputation dans la communauté et ruinerait par là ses chances de succès économique. 30366 entreprises sont détenues par des Cubains dès 1977 et représentent un chiffre d'affaires cumulé de près d'un milliard de dollars au milieu des années 1980 (Perez, 2003 : 255).

Ce système de prêt prend fin après l'épisode du Port de Mariel. Il illustre ainsi la distinction faite par les Cubains eux-mêmes entre les " populations pré et post Mariel ». Aujourd'hui on constate que les nouveaux immigrés cubains demeurent la source principale de main-d'œuvre dans l'enclave en raison de leur connaissance de la langue espagnole et de la culture cubaine. En outre, le partage de l'expérience migratoire avec leurs employeurs crée un sens du "nous» au sein de la communauté cubaine. C'est donc le capital social - basé sur l'appartenance à un groupe - qui permet aux néoarrivants de s'insérer dans l'enclave ethnique (Portes, $2002: 15$ ).

Le modèle de l'enclave ethnique défendu par Portès ne fait pourtant pas l'unanimité. Les travaux de Sanders et Nee, par exemple, montrent que les migrants cubains employés dans l'enclave ont un salaire moyen moins élevé que ceux qui travaillent en Floride, hors de l'enclave. Seuls les employeurs cubains bénéficieraient du système de l'enclave. Ils ont, pour leur part, des revenus supérieurs aux migrants employés hors de l'enclave (1987: 755). Waldinger (1993: 20) suggère que cet avantage de l'employeur cubain s'explique par la relation de clientèle qui s'installe entre le travailleur et son patron. L'assistance reçue par le travailleur migrant à son arrivée l'inciterait à accepter un emploi peu rémunéré plus longtemps. Portes a répondu à remarques en précisant qu'il n'avait jamais présenté l'enclave comme un substitut à l'intégration. Il s'agit plutôt pour lui d'une étape intermédiaire visant à favoriser l'intégration ultérieure des migrants (Portes et Jensen, 1987 : 768).

Plus récemment, Davis a confirmé les résultats de Sanders et Nee dans son analyse du recensement américain de 1990 en démontrant que les Cubains travaillant hors de Floride ont un revenu moyen supérieur aux Cubains travaillant dans l'enclave (2004: 463).

Parmi les trois types d'analyses présentées et malgré les critiques que certains auteurs ont faites à ce modèle, nous considérons qu'il reste pertinent pour expliquer la concentration cubaine à Miami. La notion de capital social permet d'expliquer la création d'une économie ethnique dans le sud de la Floride. Pourtant, dans l'analyse des activités politiques de la communauté, nous verrons que les origines sociales des migrants sont elles aussi une variable dont il faut tenir compte. 


\section{Les débuts de l'activité politique de la communauté} cubaine américaine. Dès leur arrivée en 1959, les Cubains fuyant la révolution, sont actifs sur le plan politique et il faut attendre 1980 pour voir la communauté s'impliquer dans les affaires intérieures étasuniennes. Enfin, la fin de la guerre froide signale le début d'une série de bouleversements d'ordre socio-politique au sein de la communauté.

\section{9 - 1980 : politique d'une communauté en exil}

La politique cubaine américaine des premières heures se caractérise par une forte connotation idéologique, sa préférence pour l'activisme et la gestion du retournement de la position américaine. Les premiers exilés cubains sont d'abord anti-communistes, mais pour autant leurs positions politiques ne sont pas identiques. Au cours des premières années d'exil (entre 1959 et 1964), les trois grands courants de l'opposition cubaine - les Batistanistes, les Conservateurs et les Libéraux - s'affrontent pour le leadership de la communauté. Mis à part leur hostilité à la révolution cubaine, ces groupes possèdent un second point commun: ils privilégient l'activisme au dialogue avec Washington ou la Havane. Plusieurs actions directes sont menées par les exilés contre le régime de Cuba. La première a lieu en 1959 lorsque l'opposition batistaniste soutenue par le gouvernement dominicain tente sans succès de s'emparer d'une partie de l'île. La seconde concerne l'épisode de la Baie des Cochons. Dans un effort conjoint de la CIA et de la branche conservatrice des exilés cubains, 2000 rebelles débarquent dans la Baie des Cochons à Cuba en avril 1961 dans l'espoir de s'emparer d'un morceau de terrain pour y déclarer un gouvernement provisoire, obtenir la reconnaissance du gouvernement américain et enfin son soutien militaire pour renverser le régime. Cette tentative échoue elle aussi. La troisième est menée par les Libéraux qui vont échouer dans leur tentative d'insurrection à Cuba en 1963. Les Conservateurs tirent alors profit de cette situation en associant le courant libéral au castrisme (Forment, 1998 : 54-67).

La politique américaine à l'égard de Cuba se réoriente également à la lumière de ces événements. Le faible appui du président Kennedy aux insurgés cubains dans la Baie des Cochons rompt le soutien «traditionnel » de la Maison Blanche aux exilés cubains. De plus, la crise des missiles de 1962 incite les États-Unis à plus de réserve dans son soutien à l'opposition cubaine résidant sur son territoire. Les autorités américaines suppriment leur aide aux mouvements d'opposition. L'intégration des exilés devient alors une priorité et d'importantes sommes d'argent y sont consacrées à partir de $1965^{11}$. Avec la fin du soutien américain, c'est une part de l'espoir de retourner un jour à Cuba qui s'envole pour les exilés cubains. Cette impression est confirmée par les Freedom Flights. Ce pont aérien, organisé par les États-Unis de 1965 à 1973 suite à un accord de l'administration Johnson avec Cuba, permet à 340000 réfugiés de s'installer aux États-Unis.

Par ailleurs on constate des dissensions entre les différentes factions d'exilés cubains. Une minorité va se radicaliser après «l'abandon» de Washington et va mener des actions «terroristes » ou d'intimidations. Ces activités extrémistes vont culminer en 1976 avec l'explosion d'un avion de ligne cubain transportant 73 personnes.

Revue européenne des migrations internationales, vol. 21 - n³| 2005 


\section{Le Port de Mariel et la nouvelle politique cubaine américaine}

40 l'opinion publique. Certes les WASP de Miami déplorent la transformation de leur ville, mais le succès de l'enclave est visible. L'arrivée des Marielitos (exilés du Port de Mariel) va modifier cette image. Le Miami Herald, journal des natifs blancs de Floride, entame une campagne anti-immigration cherchant d'abord à empêcher l'arrivée des Marielitos et, ensuite, à les diriger vers d'autres parties du pays. Le journal, relayant la stigmatisation faite par Fidel Castro, insiste sur la composante «indésirable » et criminelle des réfugiés de Mariel.

41 L'année 1980 est marquée par un autre événement. L'opposition WASP se mobilise pour la ratification d'un référendum interdisant l'usage de la langue espagnole dans les administrations en Floride. Ce référendum fait l'effet d'une bombe dans la communauté cubaine américaine dont l'activité politique n'avait consisté qu'à organiser la rébellion à Cuba. Cette date va marquer le début de la seconde étape de l'histoire politique cubaine américaine. Les événements survenus cette année-là sont à la base du renouveau politique cubain américain. Deux ruptures majeures l'illustrent. D'abord, la communauté cubaine américaine commence à s'impliquer dans la politique intérieure des États-Unis. Ensuite, différents groupes de pression apparaissent, poursuivant le projet d'influencer les choix de politique étrangère des autorités fédérales sur la question cubaine. Ces deux constats laissent à penser que la communauté cubaine américaine est en passe de s'établir aux États-Unis. Deux tendances anciennes se confirment néanmoins après 1980. D'une part, l'orientation politique de la communauté reste majoritairement conservatrice, d'autre part, l'anti-castrisme demeure un des piliers de la politique développée par la communauté.

\section{L'influence d'une communauté ou une communauté sous influence?}

L'implication de la communauté cubaine américaine dans la politique intérieure des États-Unis n'a pas pour but de faire reconnaître son statut de minorité ethnique par les autorités. La communauté cherche plutôt à prendre le contrôle politique des districts dans lesquels l'enclave est implantée. Elle ajoute par là un contrôle politique à l'espace qu'elle domine déjà démographiquement et économiquement. Cette ouverture à la politique intérieure américaine est donc paradoxalement un repli de la communauté sur elle-même.

D'une quasi-absence d'élus cubains américains en 1980, on passe, à la moitié de la décennie, à plusieurs mandats de maires et à dix élus à la législature fédérée. Au début des années 1980, deux élus cubains ont conquis un siège au Congrès et ont été systématiquement reconduits depuis lors (Cuban Committe for Democracy, 2003 ; Perez, 2003 : 255). Comment expliquer cette soudaine expansion de la représentation politique cubaine américaine?

Le choc créé par les événements de 1980 agit comme un déclic : la population cubaine américaine va opter de plus en plus pour la naturalisation (donnant accès au droit de vote). Elle est aidée par la législation américaine qui autorise la naturalisation après cinq ans de résidence permanente aux États-Unis. Une étude démontre que, dès 1980, la

Revue européenne des migrations internationales, vol. 21 - n³| 2005 
communauté cubaine américaine saisit cette possibilité en plus grand nombre que les autres communautés avec $46 \%$ d'immigrés naturalisés (Boswell, 2002). Outre l'accès au vote, il s'agit de souligner la participation électorale élevée dans la communauté. Enfin, le puissant sentiment d'appartenance à la communauté, perpétué par l'enclave, autorise les candidats cubains américains à penser que peu de voix cubaines iront aux candidats issus d'autres groupes.

\section{L'exemple de la Cuban American National Foundation}

La mobilisation politique des Cubains américains en 1980 se manifeste également par la naissance de la Cuban American National Foundation (CANF) dirigée jusqu'en 1997 par Jorge Mas Canosa, leader charismatique symbolisant la réussite économique cubaine. La fondation de la CANF, inspirée par le succès du lobby israélien américain, est essentiellement le fruit d'une élite économique disposée à verser chaque année 10000 dollars à l'organisation et à consacrer son temps libre au lobbying politique ${ }^{12}$. En effet, la CANF ne s'est pas créée dans l'espoir d'obtenir des fonds pour la communauté mais plutôt pour en distribuer aux mandataires en échange de leur sévérité à l'égard du régime de Castro (Portes et Stepick, $1993: 148)^{13}$. Le lobbying de la CANF lui permettra de garder longtemps une majorité du Congrès opposée à tout assouplissement de l'embargo contre Cuba. La CANF s'adresse également à la plus haute sphère du pouvoir aux États-Unis. Avant les élections présidentielles, Jorge Mas Canosa rencontrait fréquemment les candidats à Miami et leur proposait un marché finalement assez simple : $85 \%$ à $90 \%$ du vote cubain américain contre la promesse d'une attitude sévère à l'égard de Castro.

46 À l'image des opposants des années 1960, la CANF oriente son action politique vers Cuba et la chute du régime plutôt que vers l'intégration de la communauté. La différence est, qu'avec la création de la CANF et le gain de nombreux mandats politiques, la communauté cubaine américaine est désormais un acteur à part entière sur la scène politique étasunienne. Aussi, la communauté se défait-elle progressivement de son statut de communauté d'exilés.

\section{Le conservatisme dans la communauté}

Dès leur arrivée en Floride en 1959, les opposants au castrisme se partagent entre deux courants majeurs, les Conservateurs et les Libéraux. Le courant conservateur est cependant celui qui parvient à monopoliser la conduite de la politique cubaine américaine. On peut avancer deux explications à cette situation. La première concerne les relations de la communauté avec le Parti démocrate. À de nombreuses reprises, ce parti adopte une attitude jugée anti-cubaine américaine par la communauté. Cette défiance à l'égard des Démocrates trouve ses origines dans l'épisode de la Baie des Cochons durant lequel les exilés cubains se sont sentis trahis par l'administration Kennedy. Ce sentiment s'accentue lorsque cette même administration met fin au soutien des mouvements insurrectionnels cubains en exil après la crise des missiles.

L'administration Johnson ouvre la voie aux mouvements cubains américains les plus radicaux en éliminant le Mouvement Révolutionnaire du Peuple (MRP), un groupe de progressistes cubains offrant une alternative au conservatisme. Plus tard, une politique de dialogue avec Castro est soutenue par l'administration Carter et dirigée par l'exilé 
libéral Bernardo Benes. Cette politique conduit à la libération de plusieurs milliers de prisonniers cubains. Toutefois, les mouvements conservateurs de Miami craignent que ce dialogue ne conduise à une normalisation des relations entre les États-Unis et Cuba. Ils se mobilisent alors pour discréditer Benes en qualifiant le mouvement libéral cubain américain de copie du régime castriste (Desipio, $2003: 213$ ).

La gestion ambiguë de la crise de Mariel par l'administration Carter affaiblit un peu plus le Parti démocrate. En outre, le programme profondément anti-communiste du candidat Reagan accentue le vote républicain de la communauté cubaine américaine. Une fois élu, il prend une série de mesures renforçant le vote cubain américain en Floride (Ögelman, Money et Martin, 2002 : 159). Plus récemment, l'attitude du président Clinton et de son Attorney General Janet Reno sur la question du retour du petit Elian Gonzalez chez son père a accentué l'impression que les Démocrates ne sont pas favorables à la communauté.

La seconde raison de la puissance du conservatisme cubain américain réside dans le contrôle social sur l'enclave. Lorsque le président de la CANF promet de «livrer » le vote cubain américain, il s'appuie en partie sur ses grandes capacités de leader mais surtout sur l'exceptionnelle cohésion de celle-ci grâce aux liens forgés dans l'enclave (Saideman, 2002 : 98-100). L'enclave, par la proximité géographique et culturelle de ses membres, permet un contrôle social plus grand. Certains récits font part de tentatives d'intimidation par les milieux conservateurs cubains contre les individus tentés d'opter pour une attitude plus conciliante vis-à-vis du régime de Castro. Sachant qu'une telle opinion entraîne la mise au ban de la communauté et donc la perte de son emploi ou la ruine de son entreprise, peu d'individus osent défendre cette position. De même, les candidats à un mandat politique soupçonnés de frilosité dans leur opposition au castrisme peuvent oublier tout espoir d'élection. Dans ce contexte, l'activité politique de la communauté cubaine américaine se retrouve enfermée dans une spirale conservatrice qui empêche toute voix discordante de s'exprimer ${ }^{14}$. L'interrogation initiale reste donc pertinente: l'activité politique cubaine américaine reflète-t-elle l'influence d'une communauté ou plutôt l'influence des forces conservatrices sur la communauté?

\section{Les excès du renouveau politique cubain américain}

51 L'absence cubaine américaine des affaires publiques en Floride jusqu'en 1980 n'a d'égal que la force avec laquelle les nouveaux élus vont s'emparer des mandats dans le courant de la décennie. Une fois au pouvoir, les mandataires publics ne se montrent pas ingrats vis-à-vis de ceux qui les ont élus. Le return vers l'enclave se manifeste sous la forme de contrats publics adjugés en priorité aux entrepreneurs cubains américains. Un système de connivence politico-ethnique se met en place. Sa légalité est d'ailleurs mise en cause par la justice américaine dès le milieu des années 1980 (Portes, 2002 : 8-9).

Les démissions, les amendes et les peines de prison suivent, mais n'entament en rien la cohésion du vote ethnique cubain ${ }^{15}$. La CANF est elle-même impliquée dans une série de manœuvres frauduleuses ou criminelles dont une tentative d'assassinat contre Fidel Castro $^{16}$. Au-delà de ces activités illégales, ce sont les liens qu'entretient la CANF avec les autorités locales du sud de la Floride qui suscitent des interrogations sur le fonctionnement démocratique de cette région. 


\section{Nouveaux défis dans un monde post-guerre froide}

Comme nous l'avons souligné précédemment, l'activité politique cubaine américaine des années 1980 et 1990 était divisée en deux domaines: l'un, local, consistant à renforcer le pouvoir de l'enclave et l'autre national consistant à influencer la politique étrangère américaine vis-à-vis de Cuba. Cette dernière activité connaît un succès grandissant dans les années 1980. Du fait de l'action efficace de la CANF dans le démarchage de voix au Congrès, les États-Unis se montrent intransigeants à l'égard de l'embargo sur Cuba. Sans remettre en cause l'influence de la communauté cubaine américaine dans la politique d'isolement de Cuba, il faut souligner le rôle crucial joué par le rôle du président Reagan et le refroidissement des relations Est-Ouest. La relance de la lutte anti-communiste s'ajoute donc aux efforts du lobby cubain et l'action combinée de ces facteurs satisfait les ardeurs anti-castristes de la communauté. Après la disparition de l'Union soviétique, il est intéressant d'observer l'évolution du lobbying cubain privé subitement d'un contexte idéologique favorable. Ce lobby ne peut désormais compter que sur ses talents propres. Trois exemples illustrent les nouveaux défis auxquels la communauté est désormais confrontée.

\section{La loi Helms-Burton (The Cuban liberty and democratic solidarity act)}

55 La législation américaine à l'égard de Cuba n'est véritablement influencée par la communauté cubaine américaine qu'à partir de la fondation de la CANF en 1980. La même année, le Radio Broad casting to Cuba Act est voté et permet la création de Radio Marti, une station de radio diffusant des programmes non censurés à Cuba. C'est la sénatrice républicaine de Floride Paula Hawkins qui propose le texte. Cette loi est présentée comme la première grande victoire de la CANF. Une loi similaire permettant la diffusion de programmes télévisés est adoptée en 1989. Notons que la sénatrice Hawkins a reçu pas moins de 126000 dollars de contributions électorales de la CANF et de personnes privées d'origine cubaine américaine entre 1980 et 1986 (The Center for Responsive Politics, 2001).

56 L'année 1992 marque l'adoption d'un des textes les plus importants sur Cuba depuis 1962. Malgré la disparition de l'Union soviétique, le Cuban Democracy Act s'inscrit dans une logique de guerre froide. En effet, ses «parrains » au Congrès, Torricceli et Graham (tous deux démocrates), cherchaient à profiter de l'isolement de Cuba causé par la perte de l'allié soviétique pour faire chuter Castro en renforçant l'embargo ${ }^{17}$. Ces deux congressistes ont reçu, à eux deux, près de 400000 dollars de personnalités cubaines ou de la CANF pour financer leurs campagnes électorales entre 1979 et 2000 (ibid.).

57 La loi Helms-Burton adoptée en 1996 mérite notre attention à double titre. D'une part, elle survient plusieurs années après la disparition de l'URSS et, de l'autre, elle crée un précédent en droit international. Le 24 février 1996, des chasseurs MIG-29 cubains abattent deux petits avions civils américains au-dessus du Détroit de Floride. À leur bord se trouvent 4 membres de l'organisation cubaine américaine Brothers to the rescue qui venaient de lâcher des tracts anti-castristes au-dessus de la Havane. Cet incident

Revue européenne des migrations internationales, vol. 21 - n³| 2005 
convainc le président Clinton de ratifier la loi Helms-Burton à laquelle il était jusqu'alors farouchement opposé18.

Préalablement à l'approbation présidentielle de cette loi, deux congressistes de renom, Jesse Helms, représentant républicain de l'Indiana et Dan Burton, sénateur républicain de Caroline du Sud déploient toute leur énergie pour faire approuver ce texte. La CANF, par l'intermédiaire de son président Mas Canosa, multiplie les contacts dans le but de convaincre le Congrès de renforcer une fois encore les sanctions à l'égard de Castro. Le financement électoral est un autre argument utilisé par la CANF pour rallier le Congrès à sa cause. Les "parrains » du texte, Helms et Burton, ont chacun reçu plus de 20000 dollars uniquement de la CANF et bien plus encore de donateurs privés cubains américains entre 1990 et 1996 (The Center for Responsive Politics, 2001). Une étude menée sur le lobbying cubain signale, en outre, que 37 des 100 sénateurs ayant participé au vote de la loi Helms-Burton ont reçu de l'argent de la CANF à un moment de leur carrière. Vingt et un d'entre eux ont approuvé cette loi. Notons que certains sénateurs ont aussi voté le texte sans avoir jamais reçu d'argent de la CANF (ibid.). Par ailleurs, la CANF pouvait compter sur les trois congressistes cubains américains (deux républicains de Floride et un démocrate du New Jersey) parmi les plus farouches opposants au régime de Castro.

Au-delà du caractère "ethnique " de cette loi, c'est l'extrême raidissement de l'embargo qui frappe l'analyste et scandalise la communauté internationale. Le texte prévoit que toute entreprise étrangère commerçant avec des entreprises cubaines confisquées à leur propriétaire américain lors de la révolution (environ 6000 ) s'expose à des poursuites judiciaires aux États-Unis et à l'interdiction de commercer sur son territoire. Le but de cette manœuvre est d'isoler un peu plus Cuba en obligeant les entreprises étrangères à ne plus traiter avec l'île sous peine de devoir renoncer au marché américain (Lowenfeld, 1996 : 427).

60 L'Union européenne dénonce rapidement le caractère extraterritorial de la loi et menace les États-Unis de porter plainte devant l'Organisation mondiale du commerce. Le Canada et le Mexique annoncent qu'ils en feront autant selon les termes de l'Accord de libre-échange nord-américain. La controverse que suscite cette disposition dans la communauté internationale a pour conséquence que seule une application partielle de cette loi est faite, laissant au Président le soin d'autoriser l'application du principe d'extraterritorialité.

61 Plusieurs enseignements peuvent être tirés de cet épisode. D'abord, cette loi renforce l'isolement international de Cuba tout en compromettant les relations commerciales qu'entretiennent les États-Unis avec certains partenaires. Ensuite, la conjonction du financement électoral et du lobbying se révèlent être une tactique efficace. En soutenant quelques grands noms du Congrès, la CANF parvient à former un consensus sur des textes durs. Enfin, la loi Helms-Burton conforte le sentiment que l'activité politique cubaine américaine au niveau fédéral se concentre sur des questions de politique étrangère et non sur l'intégration de la communauté dans le pays d'accueil.

62 En dépit de la fin de la guerre froide, la CANF continue donc à convaincre les autorités américaines de l'utilité d'une attitude sévère à l'égard de Cuba. Elle est aidée en cela par des événements à forte connotation émotionnelle comme le décès des quatre militants anti-castristes abattus par l'armée cubaine. 


\section{L'affaire Elian Gonzalez}

63 Floride où le naufrage de son embarcation cause la mort de onze passagers - dont sa mère - fuyant Cuba. L'enfant est remis à sa famille maternelle de Miami qui introduit rapidement une demande d'asile. Peu après, son père, divorcé et remarié, réclame son retour à Cuba. S'ensuit une bataille juridique de sept mois au terme de laquelle la garde de l'enfant est retirée à sa famille cubaine américaine et donnée à son père par l'Immigration and Naturalization Service (INS).

64

Ces événements vont susciter la réaction de la communauté cubaine américaine et de l'opinion publique par l'intermédiaire des médias et des autorités américaines. L'aspect émotionnel de cette affaire prend rapidement le dessus au sein de la communauté cubaine américaine. Il ne s'agit pas, pour elle, d'une simple histoire de garde parentale comme il en arrive fréquemment. Il s'agit plutôt de l'histoire d'un enfant innocent pour lequel une mère s'est sacrifiée afin de le soustraire au régime de Fidel Castro. Durant plusieurs mois, des membres de la communauté se relaient devant la maison de Miami - située au cœur du quartier cubain - où réside Elian. Ils tenteront finalement de faire obstacle à l'intervention policière qui a rendu le petit garçon à son père.

Derrière l'apparente unité de la communauté cubaine américaine se cache cependant une division profonde. Le document vidéo «Saving Elian » réalisé par Ofra Bikel montre que, parmi les manifestants affichant leur soutien à la famille américaine d'Elian, beaucoup avouent secrètement qu'il serait plus juste que l'enfant rentre avec son père (PBS Frontline, 2000). Ils soulignent aussi le fait qu'une telle opinion ne peut être défendue publiquement devant la communauté. Cet élément confirme l'existence de la «spirale conservatrice» mentionnée au sujet de l'enclave. Un contrôle social fort empêche les membres de la communauté d'émettre des opinions susceptibles d'être taxées de "pro-castristes" sous peine de perdre le bénéfice socioéconomique de l'enclave. Même si ces opinions divergentes restent discrètes, il est difficile de contester leur existence. L'arrivée croissante de réfugiés économiques depuis 1980 explique en partie cette évolution.

66 Le rôle des médias a également été capital dans la formation de l'opinion publique américaine sur la question de la garde d'Elian. Sur 432 reportages concernant les Hispano-américains dans les journaux télévisés du soir de $A B C, C B S, N B C$ et $C N N$ en 2000, 348 ont été consacrés à Elian. À titre de comparaison, seuls 162 reportages avaient été réalisés sur les Hispaniques en 1999 (National Association of Hispanic Journalists, 2001 : 5) ${ }^{19}$. Ces chiffres illustrent l'ampleur médiatique de cet épisode.

La couverture de l'événement aux États-Unis n'a d'équivalent que l'échec de la bataille des images pour la communauté cubaine américaine. L'opinion publique refuse de voir en Elian le symbole de la lutte contre Castro. L'extrémisme dont fait preuve la communauté durant cet épisode, dont les affrontements avec la police et les blocages des routes, du port et de l'aéroport sont les meilleures illustrations, écorne sérieusement son image et crée de surcroît des tensions ethniques à Miami (Portes, 2002). Cet événement concourt à faire réfléchir l'opinion publique américaine sur l'opportunité de poursuivre l'embargo sur Cuba.

68 Un sondage réalisé par l'Université Internationale de Floride prouve d'ailleurs que $82 \%$ des Cubains américains de Miami pensent que l'Affaire Elian a nui à leurs intérêts (Cuban Research Institute, 2000). La défaite médiatique n'est cependant pas totale pour la 
communauté cubaine américaine. En effet, bien qu'elle soit dépeinte comme extrémiste, l'action des mouvements anti-castristes de Miami a été répercutée à travers le monde. Cette couverture à l'échelle planétaire est un formidable coup de projecteur sur leur lutte. Elle rappelle qu'il existe une dictature à Cuba, à un moment où certains gouvernements occidentaux sont tentés de normaliser leurs relations avec lî̂le.

La réaction de l'opinion publique américaine ne laisse toutefois pas les autorités sans voix. Au Congrès, où certains élus souhaitent voir l'embargo assoupli, l'image de la communauté est ternie suite à cette affaire. En d'autres termes, l'opinion publique et une partie de la classe politique américaine refusent d'entrer dans la logique de guerre froide encore défendue par une partie de la communauté. Il s'agit là d'un tournant puisque, auparavant, les candidats à une élection nationale pouvaient supporter les positions dures de la communauté cubaine américaine sans craindre de perdre le soutien d'autres groupes par ailleurs peu intéressés par cette question (Moore 2002 : 84).

\section{Les présidentielles de 2000 et les nouveaux défis de la politique cubaine américaine}

Le troisième aspect qu'il convient d'analyser dans l'activité politique cubaine américaine post-guerre froide a trait à une série d'événements qui concernent l'approbation de la loi Helms-Burton et les élections présidentielles de $2000^{20}$.

71 En novembre 1997 le décès de Jorge Mas Canosa, président de la CANF, va poser la question du leadership de l'organisation et de la communauté dans son ensemble. En effet, bien qu'étant un personnage controversé, Mas Canosa avait réussi à se faire accepter autant par les immigrés de l'enclave que par les représentants du Congrès. Les deux congressistes floridiens Diaz-Balart et Ros-Lehtinen étaient pressentis à sa succession mais c'est finalement le fils de Mas Canosa, Jorge Mas Santos, qui prend sa succession.

Le fait que le nouveau président de la CANF soit né aux États-Unis et ne se soit jamais rendu à Cuba permet d'introduire la question de la participation au combat politique de la seconde génération cubaine américaine. Deux points se présentent: le premier met l'accent sur la transmission à la nouvelle génération de la haine des parents à l'égard de Castro (Portes, 2002: 13), le second insiste sur les spécificités de cette nouvelle génération née aux États-Unis tout autant cubaine qu'américaine. Elle maîtrise la langue anglaise et est plus qualifiée, donc plus en situation de trouver un emploi hors de l'enclave. Enfin, elle ne connaît l'expérience de l'exil que par les récits qui lui en ont été faits ${ }^{21}$. La seconde génération n'a pourtant pas tourné le dos à la lutte engagée par les parents, mais son point de vue est différent notamment sur la question de l'isolement de Cuba. Le nouveau leader de la CANF reconnaît en effet une tendance à la modération politique plutôt qu'au conservatisme parmi la seconde génération et les nouveaux immigrés économiques cubains.

La première manifestation de cette ouverture se fait en 1998 lorsque, sous l'impulsion de la CANF, le sénateur Helms propose un texte destiné à verser l'aide humanitaire américaine pour Cuba à des organisations non-gouvernementales de manière à s'assurer qu'elle profitera à la population cubaine et non au régime. Cette loi ne remet pas en cause l'embargo, mais elle consacre un nouveau principe dans la politique cubaine américaine: maintenir l'isolationnisme tout en réduisant ses effets sur le 
peuple cubain. Le président Clinton et le Département d'État veillent également à maintenir les sanctions qui frappent uniquement le régime. Pour cette raison, ils prennent différentes mesures en 1999 pour faciliter le transfert d'argent des Cubains américains vers leurs familles, faciliter les voyages vers Cuba avec une autorisation, et d'autres mesures destinées à l'égard du peuple cubain lourdement frappé par la crise économique (Brenner, Haney et Vanderbush, 2002 : 195).

Pendant longtemps, l'envoi d'argent ou les visites familiales à Cuba (possible en contournant l'embargo par le passage via des pays tiers) ont été considérés comme des actes de trahison envers la communauté cubaine américaine. L'arrivée de réfugiés économiques décidés à supporter leurs proches restés au pays a joué un rôle déterminant à cet égard. En 2002, environ la moitié des exilés cubains a envoyé des remises d'épargne aux proches restés à Cuba. On estime, en outre, que Cuba a bénéficié en 2003 d'un total de 1,138 milliard de dollars de remises d'épargne en provenance de ses émigrés (Inter American Development Bank, 2003). Ce chiffre est supérieur aux estimations de 1995 de l'ordre de 300 à 400 millions de dollars annuellement (DiazBriquets et Perez-Lopez, 1997 : 437). Cette ouverture, conjuguée au maintien de l'embargo, correspond aux attentes contradictoires d'une majorité de la population cubaine américaine du sud de la Floride (voir plus bas).

Parallèlement à la relative ouverture de la CANF et au travail du président Clinton, un consensus se crée au sein du Congrès en faveur de l'assouplissement- voire la levée pure et simple - de l'embargo. Ce changement d'attitude du Congrès, jusqu'alors relativement peu enclin à discuter de toute révision profonde de l'embargo, est dû aussi à l'action de groupes de pression. Les agriculteurs et les entreprises américaines, par l'intermédiaire du Farm Bureau et de la Chambre de Commerce des États-Unis, désirent en effet voir les sanctions s'assouplir ou disparaître. Face à ces forces, la CANF se retrouve dans la position de devoir défendre ses acquis. La vente de nourriture en l'échange d'un paiement en liquide est cependant autorisée. 165 millions de dollars de vivres sont vendus à Cuba entre 2000 et 2002. Ce montant fait des États-Unis le dixième partenaire commercial de Cuba alors qu'officiellement, l'embargo est toujours en vigueur.

76 Le second fait significatif concerne l'Affaire Elian Gonzalez. Celle-ci a eu un effet involontairement positif sur la communauté. Elle a rappelé aux gouvernants l'importance du vote cubain américain lors des scrutins. Lorsqu'en 2000, le président Clinton et son Attorney General Janet Reno prennent position en faveur du retour de l'enfant à Cuba, ils placent le vice-président et le candidat démocrate Albert Gore dans une situation délicate. Ce dernier prend alors la décision de se désolidariser de la décision de son administration pour préserver ses chances de gagner le vote cubain américain.

Le candidat républicain George Walker Bush, fidèle à l'alliance de son parti avec la communauté, condamne lui aussi cette décision. La stratégie du candidat Gore se révèle infructueuse car la communauté ne lui pardonne pas la décision du président Clinton. Cette décision est perçue comme la suite d'une longue série de mesures anti-cubaines américaines prises par les administrations démocrates depuis 1961. Une partie de l'électorat cubain américain lors des présidentielles de 2000 est donc motivée par le désir de sanctionner les démocrates pour leur gestion de l'affaire Elian. La CANF soutient quant à elle que, si Gore avait obtenu les voix cubaines américaines que Clinton avait réussies à attirer en 1996 (année où il approuva la loi Helms-Burton), il 
aurait pu remporter les élections en Floride. Sachant le rôle déterminant de cet État lors du scrutin de 2000 , on peut se demander si le vote cubain n'a pas précipité la défaite du candidat démocrate.

D'autres éléments attestent du poids de la communauté dans cette élection. Par exemple, le fait que les districts à majorité afro-américaine aient été plus touchés que les autres par les invalidations de bulletins renforce l'importance du vote républicain des Cubains américains. De plus, des manifestants Cubains américains ont exigé, sur le conseil de leurs deux congressistes républicains, que le second comptage des voix du comté de Miami-Dade soit interrompu; ce qui laisse deviner la détermination d'une partie de la communauté à voir le candidat Bush triompher.

79 En conclusion, attribuer la victoire du président Bush au vote massivement républicain ${ }^{22}$ des Cubains est difficilement vérifiable. Cependant, on a constaté une perte de 70000 voix démocrates uniquement dans le comté de Miami-Dade, celui où se situe l'enclave.

\section{La communauté et l'administration Bush : confirmation des tendances ? ${ }^{23}$}

Le radicalisme cubain dans l'Affaire Elian a eu pour conséquence d'inciter le Congrès à écouter les voix des partisans de l'assouplissement de l'embargo. Cette déroute de la politique cubaine américaine a également conduit la CANF à s'interroger sur l'efficacité de son action. Dès septembre 2000, l'organisation décide de quadrupler les montants qu'elle octroie aux dissidents résidant à Cuba.

81 Ce geste révèle une tentative de changement d'orientation de son action vis-à-vis de La Havane (et un peu moins vers le Congrès). Un peu plus tard, la CANF décide de répartir ses donations électorales plus équitablement entre démocrates et républicains. Une «Ambassade pour un Cuba libre » est également ouverte à Washington D.C. dans le but de redorer l'image de la communauté. Cette réorientation, initiée par la nouvelle direction de la CANF, déplaît aux membres fondateurs. Vingt-deux membres du conseil d'administration décident de quitter la CANF. Cette rupture est tout aussi idéologique que générationnelle. Les «Anciens » ne peuvent admettre qu'une politique autre que l'isolement de Castro soit défendue. Les membres issus de la seconde génération, quant à eux, s'interrogent sur l'efficacité d'une politique qui, en quarante années d'existence, n'a pas permis de faire tomber le Líder Máximo. Au contraire, ils estiment que Castro en a profité pour maintenir sa population en état de mobilisation face à un ennemi extérieur. Après le départ de la CANF, les hard liners (partisans de la ligne dure) fondent le Cuban Liberty Council (CLC). Le CLC continue d'opposer une résistance farouche au dialogue avec Cuba et souhaite interdire l'envoi d'argent des exilés vers leur famille, de même que les vols vers Cuba. Entre les conservateurs, ayant montré par le passé qu'ils se mobilisent efficacement lors des scrutins, et les forces modérées en train de se constituer, Washington est forcé de choisir. La communauté attend en effet que le président Bush la récompense pour son soutien lors de l'élection.

82 La première mesure significative que prend le président Bush est de nommer le Cubain américain Otto Reich comme Assistant du Secrétaire d'État en charge de l'Amérique Latine en janvier $2002^{24}$. Cette nomination, ajoutée aux menaces d'opposer son veto à toute mesure d'assouplissement de l'embargo, est saluée par les hard liners du CLC. Otto 
Reich, ancien ambassadeur des États-Unis au Venezuela soupçonné d'être lié à l'affaire des Contras, se voit reprochées certaines amitiés avec des terroristes cubains américains. Cela conduit les sénateurs démocrates à bloquer temporairement sa nomination sans toutefois l'empêcher d'exercer ses fonctions. C'est seulement un an plus tard que démocrates et républicains s'opposent définitivement à sa nomination. À sa place, le président Bush propose Roger Noriega, protégé du sénateur Helms et anticastriste notoire.

En 2003, le Président annonce la mise en place d'une commission sur Cuba dirigée par le secrétaire d'État Colin L. Powell et le secrétaire au logement et au développement urbain - et ancien membre de la CANF - Mel Martinez ${ }^{25}$. Comme l'a annoncé le président Bush, l'objectif de cette commission est de préparer la transition de Cuba d'un régime autoritaire vers une société libre et ouverte.

Le rapport de la commission est rendu public en mai 2004 et, dès le mois de juin, le président Bush prend une série de mesures recommandées par la commission. Parmi ces mesures, deux touchent de près la vie de la communauté cubaine américaine. La première consiste à limiter les déplacements vers Cuba des Cubains résidant aux ÉtatsUnis à un seul voyage tous les trois ans et cela uniquement pour visiter un parent en ligne directe. La doctrine américaine selon laquelle les visites de ses ressortissants à Cuba sont de nature à affaiblir le régime n'est donc plus de mise (Mahler, $2000: 202$ ). La seconde mesure concerne l'envoi de remises d'épargne et de colis vers Cuba. Ces envois sont eux aussi limités à la famille proche et ne peuvent, dans le cas des colis, dépasser la valeur de 200 dollars $^{26}$.

Une analyse traditionnelle de la communauté voudrait que les migrants arrivés avant 1980 perçoivent le durcissement de la position américaine à l'égard de Cuba comme un facteur permettant de précipiter la chute de Castro. De plus, selon cette analyse, les néo-arrivants et la seconde génération s'opposeraient à ces mesures. Selon eux, elles seraient nuisibles aux intérêts de leurs proches restés à Cuba et sans effets sur la chute du régime castriste.

Un sondage mené par l'Université Internationale de Floride peu avant l'entrée en vigueur des nouvelles restrictions, suggère toutefois que les divisions dans la communauté cubaine américaine ne sont plus aussi tranchées. Bien que $74,4 \%$ des Cubains du sud de la Floride reconnaissent que l'embargo n'a jusqu'ici pas fonctionné, $66,1 \%$ d'entre eux souhaitent son maintien, $51,8 \%$ s'opposent à la possibilité de voyager sans restriction vers Cuba et 53,6\% affirment envoyer de l'argent à des proches restés à Cuba (Cuba Research Institute, 2004). Tout en restant prudent face à ces résultats, on peut en tirer deux enseignements. D'abord, une partie non quantifiable des néoarrivants est favorable à l'embargo, bien qu'ils soient considérés comme plus modérés que les autres. Ensuite, environ la moitié des Cubains du sud de la Floride souhaiterait voyager et envoyer de l'argent plus librement vers Cuba. Cette partie de la communauté est donc bien celle qui est en désaccord avec les nouvelles mesures du président Bush.

Le président a donc pris position en faveur des hard liners de la communauté cubaine américaine. Cette mesure peut paraître maladroite si l'on examine la composition de la communauté formée aujourd'hui approximativement d'autant de néo-arrivants (après 1980) et de Cubains de la seconde génération d'une part, que d'anciens immigrés de l'autre. On peut donc se poser la question de savoir si le président Bush ne tourne pas ainsi le dos à une partie de l'électorat cubain? 
On peut avancer deux explications pour comprendre le choix du Président. D'abord, à quelques mois de l'élection présidentielle de 2004, il se devait d'agir dans le dossier cubain. Comme nous l'avons déjà dit, la communauté cubaine américaine estime que le Président leur doit son premier mandat et attend d'en être récompensée. Ensuite, le choix du Président pour les hard liners relève également d'un calcul politique. Les hard liners sont, en effet, plus fidèles au parti républicain et plus gros donateurs de financement électoral que leurs homologues modérés. Mais surtout, les modérés généralement arrivés plus tardivement en Floride, ne sont pas tous en droit de voter ${ }^{27}$. À quelques mois des Présidentielles de 2004, ces arguments ont certainement pesé sur le choix du président Bush.

Si l'on analyse les résultats du scrutin présidentiel de 2004 en Floride, ce choix s'est révélé pertinent. Le président Bush a en effet remporté les élections avec 52,1\% des voix contre $47,1 \%$ des voix pour le candidat John F. Kerry. Il s'agit là d'une progression depuis sa victoire par 538 voix d'écart en 2000. Toutefois, il est malaisé d'identifier le poids du vote cubain américain dans cette victoire. En effet, le sondage réalisé à la sortie des urnes par l'institut William C. Velasquez (2004) laisse penser qu'une partie de cet électorat s'est détournée du candidat républicain. $60,3 \%$ des électeurs cubains américains auraient voté pour le président Bush et $38,2 \%$ pour le candidat Kerry. En 2000 , le candidat Bush avait rassemblé $81 \%$ du vote cubain contre $17 \%$ pour le candidat Al Gore. En outre, l'évolution du vote cubain semble aller à l'encontre du vote hispanique. Ce dernier, bien que toujours majoritairement démocrate, est devenu un peu plus républicain que quatre ans auparavant ${ }^{28}$.

Quelques mois après l'élection, on peut seulement avancer des hypothèses pour expliquer la particularité du vote cubain. La première a déjà été évoquée dans cet article. Il s'agit de l'augmentation du nombre d'électeurs cubains de seconde génération ou récemment arrivés et venant d'acquérir le droit de vote. De scrutin en scrutin, la part de cette population dans l'électorat cubain américain gagne en importance. Cette population qui diffère des migrants arrivés avant 1980 par ses motivations économiques et par sa vision du régime en place à Cuba est plus encline à voter pour un candidat présidentiel prônant une politique modérée à l'égard de Cuba. La seconde hypothèse fait référence à un changement plus profond dans la communauté cubaine américaine. Une courte majorité de Cubains américains affirme encore que la politique cubaine des candidats présidentiels est très importante dans leur choix. Toutefois, des statistiques laissent à penser que le vote cubain est aujourd'hui plus influencé par d'autres préoccupations qu'auparavant. $23 \%$ des électeurs cubains affirment en effet que les questions de l'avortement et du mariage homosexuel ont joué un rôle prépondérant dans leur vote. Ils se démarquent par là nettement des électeurs hispaniques en général. Ils se rapprochent en revanche de la moyenne nationale qui, à $22 \%$, affirme que les valeurs morales ont été déterminantes dans leur choix. En revanche, la question de l'économie et de l'emploi importe seulement à $10 \%$ des électeurs cubains contre environ $20 \%$ pour l'électorat hispanique et national (William C. Velasquez Institute, 2004).

91 Malgré les réserves d'usage à l'égard des sondages d'opinions, il semble qu'une combinaison de ces deux hypothèses doive guider les recherches futures sur cette communauté. Ces hypothèses confirment, en effet, les changements au sein de la communauté depuis la fin des années 1990. L'effet combiné du changement démographique de l'électorat cubain et de la diversification des préoccupations 
déterminant son vote sont deux pistes à suivre lors des prochains scrutins. Une manière de donner du sens à ces changements est de les replacer dans l'évolution du statut de la communauté cubaine américaine. Elle serait passée d'une communauté d'exilés à une communauté ayant des pratiques transnationales.

\section{Conclusion : transnationalisme et politique cubaine américaine}

Nous avons vu que les premiers Cubains à quitter l'île, lors de la révolution, faisaient partie de l'élite du pays. Avant l'exil, certains de ses membres se rendaient déjà régulièrement à Miami pour des raisons professionnelles ou privées. Mais cette situation ne permet toutefois pas d'affirmer que des pratiques transnationales existent de longue date au sein de la communauté. En effet, alors que l'activité réelle de cette communauté est exclusivement tournée vers Cuba, les États-Unis ne sont considérés que comme leur base de repli. La crise des missiles de Cuba ancre un peu plus la communauté dans sa société d'accueil en éloignant toute perspective de retour vers Cuba à court et moyen terme.

Progressivement, les exilés vont construire l'enclave dont on peut penser qu'elle jette les bases du transnationalisme cubain américain. Le succès économique de l'enclave attire les réfugiés économiques de Cuba qui, à l'image d'autres communautés immigrées, partent dans l'espoir de venir en aide aux proches restés au pays. C'est parmi ces nouveaux immigrés et parmi la seconde génération cubaine américaine que l'on voit émerger des pratiques transnationales.

94 Ces deux groupes renoncent aux actions violentes et reconnaissent que l'avenir de Cuba se joue à la Havane et non à Miami. Ce faisant, le statut de la communauté évolue progressivement. La communauté cubaine américaine $d u \mathrm{xxI}^{\mathrm{e}}$ siècle n'est plus uniquement une communauté d'exilés attendant de reprendre le pouvoir à Cuba ou un groupe ethnique dont le lobbying est sa seule activité politique. La communauté cherche toujours à assurer son bien-être économique dans l'enclave, mais désire l'étendre aux proches restés au pays.

La situation politique à Cuba reste pour eux une préoccupation majeure, mais la communauté prend conscience qu'elle doit agir en concertation avec l'opposition cubaine présente sur l'île. Elle dépasse par là le modèle du groupe de pression ethnique cherchant à utiliser les institutions du pays d'accueil pour provoquer le changement dans son pays d'origine. La conséquence de ces nouvelles pratiques est qu'un espace transnational pourrait se construire aujourd'hui entre Cuba et la Floride ${ }^{29}$.

En outre, si l'on utilise la définition du transnationalisme politique " par l'impact », on peut considérer que ce type de pratique prend source dans les activités de la communauté durant les années $1980^{30}$. En effet, le poids du lobbying ethnique sur le Congrès a eu de lourdes conséquences sur l'île. La réaction de Fidel Castro, qui considère les Cubains de Miami comme ses principaux ennemis politiques, atteste d'ailleurs de cet impact.

97 Par la suite, l'assouplissement de l'embargo entamé lors du second mandat du président Clinton a eu pour conséquence d'augmenter les aides financières versées par les Cubains américains à leurs proches. Cet assouplissement a également facilité les visites d'exilés dans leur pays d'origine. Le mouvement est relayé par l'arrivée de la 
nouvelle génération à la tête de la CANF. Elle comprend l'importance du fossé qu'a creusé l'Affaire Elian avec l'opinion publique américaine et entame une réflexion sur la politique cubaine américaine. Il en résulte une fragmentation dans la communauté entre les partisans de la sévérité et les modérés. Ces derniers souhaitent réorienter la politique cubaine américaine vers Cuba; favorisant de la sorte l'émergence de pratiques transnationales. Le clivage est encore plus net à l'été 2004 lorsque le président Bush annonce le renforcement des mesures restrictives à l'égard de Cuba. L'accueil réservé à ces mesures par les Cubains du sud de la Floride révèle ces dissensions au grand jour.

Le combat entre ces deux tendances est aujourd'hui important au sein de la communauté. Le résultat des présidentielles de 2004 semble encore donner l'avantage aux hard liners malgré l'effritement du vote républicain. Si le rôle des changements démographiques a été évoqué, l'hypothèse a été également émise que le vote républicain n'est désormais plus exclusivement motivé par la position anti-castriste défendue par ce parti. La combinaison de ces deux hypothèses rend incertaine toute prédiction sur l'orientation politique de la communauté cubaine américaine à l'avenir. Cette incertitude a toutefois une conséquence certaine : le vote cubain de Floride sera, pour un certain temps encore, courtisé par les candidats démocrates et républicains à l'élection suprême.

\section{BIBLIOGRAPHIE}

AUDEBERT Cédric (2000) Miami, porte d'entrée de la Caraïbe aux États-Unis, in M. BURAC et A. CALMONT (dirs.), La question de la terre dans les colonies et départements français d'Amérique, Paris, Karthala, pp. 375-418.

ABRAHAM David (2001) Gonzalez ex rel. v. Reno, The American Journal of International Law, 95 (1), janvier 2001, pp. 204-212.

BOSWELL Thomas D. (2002) A demographic profile of Cuban Americans, Cuban American National Council, http://www.cnc.org/demographicprofile.html. Adresse consultée le 15 juin 2003.

BRENNER Philip, HANEY Patrick J. et VANDERBUSH Walter (2002) The confluence of domestic and international interests : U.S. policy toward Cuba, 1998-2001, International Studies Perspective, 3 , pp. 192-208.

CONTRERAS Joseph (2000) Covering Elian in print. How did the Miami media do it ?, Harvard International journal of press and Politics, 5 (4), pp. 123-127.

CUBAN COMMITTEE FOR DEMOCRACY « The face of Cuban immigration : An Interview with Alejandro Portes », http://www.us.net/cuban/cubanaffairs/immigration.html. Adresse consultée le 14 juin 2003.

CUBAN RESEARCH INSTITUTE (2000) FIU Cuba Poll : comparison of three samples, http:// www.fiu.edu/orgs/ipor/cuba2000/3samples.htm, Adresse consultée le 10 juin 2003. 
CUBAN RESEARCH INSTITUTE (2004) « FIU Cuba Poll », - http://www.fiu.edu/orgs/ipor/ cubapoll/index.html, Adresse consultée le 15 décembre 2004.

DAVIS Carla P. (2004) Beyond Miami : The ethnic enclave and personal income in various Cuban communities in the United States, International Migration Review, 38 (1), pp. 450-469.

DESIPIO Louis (2003) Cuban Miami : Seeking Identity in a political borderland, Latin American Research review, 38 (2), pp. 207-219.

DIAZ-BRIQUETS Sergio et PEREZ-LOPEZ Jorge (1997) Refugee remittances : Conceptual issues and the Cuban and Nicaraguan experiences, International Migration Review, 31 (2), pp. 411-437.

FAIST Thomas (2000) The volume and dynamics of international migration and transnational social spaces, Oxford, Clarendon Press, $380 \mathrm{p}$.

FORMENT Carlos A. (1989) Political practice and the rise of an ethnic enclave : The Cuban American case, 1959-1979, Theory and Society, 18 (1), pp. 47-81.

GIRAULT Christian (2003) Miami, Capitale du Bassin Caraïbe, Mappemonde, 72, pp. 29-33.

HANEY Patrick J. et VANDERBUSH Walter (1999) The role of ethnic groups in U.S. foreign policy : The case of the Cuban American National Foundation, International Studies Quarterly, 43, pp. 341-361.

HEINDL Brett S. (2003) Debating the embargo : Transnational political activity in the CubanAmerican community, 1959-1997, Berkeley Journal of Sociology, 47, pp. 76-104.

INTER AMERICAN DEVELOPMENT BANK (2003) Community remittances and local development, http://idbdocs.iadb.org/wsdocs/getdocument.aspx?docnum=558849, Adresse consultée le 15 décembre 2004 .

LAFLEUR Jean-Michel (2005) Le transnationalisme politique. Pouvoir des communautés immigrées dans leurs pays d'accueil et pays d'origine, Louvain-la-Neuve, Academia-Bruylant, 76 p.

LOWENFELD Andreas F. (1996) Congress and Cuba : The Helms-Burton Act, The American journal of international law, 90 (3), pp. 419-434.

MAHLER Sarah J. (2000) Constructing international relations : The role of transnational migrants and other non-state actors, Identities, 7 (2), pp. 197-232.

MOHL Raymond A. (1985) An Ethnic « boiling pot »: Cubans and Haitians in Miami, The Journal of Ethnic Studies, 13 (2), pp. 52-56.

MOORE Will H. (2002) Ethnic minorities and foreign policy, SAIS Review, (12) 2, pp. 77-91.

NATIONAL ASSOCIATION OF HISPANIC JOURNALISTS (2001) Network Brownout : A portrait of Latinos in network television news, http://www.nahj.org/pdf/brownout.pdf, Adresse consultée le $1^{\mathrm{er}}$ juillet 2003.

ÖGELMAN Nedim, MONEY Jeannette et MARTIN Philip (2002) Immigrant cohesion and political access in influencing foreign policy, SAIS Review, (12) 2, pp. 145-165.

OLSON William C. (1991) The U.S. Congress : An independent force in world politics ?, International Affairs, 67 (3), pp. 547-563.

PBS FRONTLINE (2000) Saving Elian, http://www.pbs.org/wgbh/pages/frontline/shows/elian/, Adresse consultée le 25 juin 2003.

PEDRAZA-BAILEY Silvia (1985) Cuba's Exiles : Portrait of a refugee migration, International Migration Review, 19 (1), pp. 4-34. 
PEREZ Louis. A. (2003) Cuba and the United States: Ties of singular intimacy, $3^{\text {ème }}$ édition, Athens, The University of Georgia Press, $336 \mathrm{p}$.

PORTES Alejandro (2002) The Cuban-American political machine : Reflections on its origins and perpetuation, Center for Migration and Development at the University of Princeton, http:// cmd.princeton.edu/papers/wp0202.pdf., Adresse consultée le 17 juin 2003.

PORTES Alejandro (1984) The rise of ethnicity : Determinants of ethnic perceptions among Cuban exiles in Miami, American Sociological Review, (49) 3, pp. 383-397.

PORTES Alejandro, GUARNIZO Luis E. et LANDOLT Patricia (1999) « The study of transnationalism : pitfalls and promise of an emergent research field », Ethnic and racial studies, 22 (2), pp. 217-237.

PORTES Alejandro et JENSEN Leif (1987) What's an ethnic enclave ? The case for conceptual clarity, American Sociological Review, 52, pp. 768-771.

PORTES Alejandro et JENSEN Leif (1989) The enclave and the entrants : Patterns of ethnic enterprise in Miami before and after Mariel, American Sociological Review, 54 (6), pp. 929-949.

PORTES Alejandro et MOZO Raphael (1985) The political adaptation process of Cuban and other ethnic minorities in the United States : A preliminary analysis, International Migration Review, 19 (1), pp. 35-63.

PORTES Alejandro et STEPICK Alex (1985) Unwelcome Immigrants : The labour market experience of 1980 (Mariel) Cuban and Haitian refugees in South Florida, American Sociological Review, 50, pp. 493-514.

PORTES Alejandro et STEPICK Alex (1993) City on the edge. The transformation of Miami, Berkeley and Los Angeles, University of California Press, $281 \mathrm{p}$.

PORTES Alejandro, STEPICK Alex et TRUELOVE Cynthia (1986) Three years later : the adaptation process of 1980 (Mariel) Cuban and Haitian Refugees in South Florida, Population Research and Policy Review, 5, pp. 83-94.

SAIDEMAN Stephen M. (2002) The power of the small : The impact of ethnic minorities on foreign policy, Sais Review, 12 (2), pp. 93-105.

SANDERS Jimy M. et NEE Victor (1987) Limits of ethnic solidarity in the enclave economy, American Sociological Review, 52, pp. 745-773.

SHAIN Yossi (1999) Marketing the American creed abroad-Diasporas in the U.S. and their homelands, Cambridge, Cambridge University Press, 295 p.

SMITH Tony (2000) Foreign Attachments -The power of ethnic groups in the making of American foreign policy, Cambridge, Harvard University Press, 190 p.

THE CENTER FOR RESPONSIVE POLTICS (2001) The Cuban Connection : Cuban American money in US elections 1979-2000, -http://www.opensecrets.org/pubs/cubareport/legislation.asp, Adresse consultée le 12 avril 2003.

US CENSUS BUREAU (2001) Census 2000 brief : Overview of race and Hispanic origin, http:// www.census.gov/prod/2001pubs/cenbr01-1.pdf, Adresse consultée le 15 décembre 2004.

VARGAS LLOSA Alvaro (1997) El exilio indomable, Madrid, Hoy, 424 p.

WALDINGER Roger (1993) Le débat sur l'enclave ethnique : revue critique, Revue Européenne des Migrations Internationales, 9 (2), pp. 15-29. 
WALDINGER Roger (1994) The making of an immigrant niche, International Migration Review, 28

(1), pp. 3-30.

WARREN Christopher L., STACK John F., CORBETT John G. (1986) Minority mobilization in an international city : Rivalry and conflict in Miami, PS, 19 (3), pp. 626-634.

WILLIAM C. VELASQUEZ INSTITUTE (2004) 2004 National exit poll- Non-Cuban versus Cuban Latino voters, -http://www.wcvi.org/latino_voter_research/polls/national/2004/crosstabs/ cuban.html, Adresse consultée le 20 décembre 2004.

WILSON Kenneth L. et MARTIN W. Allen (1982) Ethnic Enclaves : A comparison of the Cuban and Black Economies in Miami, The American Journal of Sociology, 88 (1), pp. 135-160.

\section{NOTES}

1. L'auteur souhaite remercier Jean-Louis Micha, Benoît Lafleur, Hassan Bousetta et Philippe Knaepen pour leurs commentaires. La REMI remercie Cédric Audebert pour la révision de l'article.

2. Nous parlons de communauté "cubaine américaine» et non «cubano-américaine " pour insister, comme cela se fait dans la littérature sur le transnationalisme, sur le caractère dual de l'identité communautaire.

3. Key West, la ville la plus méridionale des États-Unis, se situe à environ 150 kilomètres de la Havane.

4. Les États-Unis s'étaient déclarés neutres dans ce conflit jusqu'en 1897 lorsque le bâtiment de guerre Maine explose dans le port de la Havane.

5. Ce programme fédéral, mis en place trois mois après l'échec de la Baie des Cochons, a fonctionné entre 1961 et 1981 . Son but était de recenser les réfugiés cubains et de leur venir en aide. Depuis le Cuban Refugee Center de Miami, les autorités américaines offraient notamment aux réfugiés des soins médicaux, de la nourriture, une aide financière ou une formation professionnelle.

6. Les estimations quant au nombre de ces exilés de force varient entre $10 \%$ et $40 \%$ des réfugiés du Port de Mariel.

7. L'accord de 1994 est le résultat d'une crise migratoire durant l'été. Les conditions économiques se détériorant dans le pays, de nombreux Cubains cherchent à le quitter. En août 1994, une série de bateaux sont détournés dans le port de la Havane par des candidats à l'émigration. Face à cette violence, les autorités cubaines donnent, comme en 1980, la possibilité à tout citoyen de quitter le pays. Au contraire de l'épisode de Mariel, Washington n'est plus disposé à accueillir ces immigrés à bras ouverts. Les deux gouvernements ont par conséquent signé cet accord afin de contrôler les mouvements migratoires.

8. Le terme " hispanique » fait ici référence à la définition retenue par le U.S. Census. Il s'agit de «toute personne d'origine ou de culture cubaine, mexicaine, portoricaine, sud ou centreaméricaine, ou de toute autre origine ou culture espagnole indépendamment de sa race " (US Census Bureau, $2001: 2$; ma traduction).

9. L'épisode de l'invasion ratée de la Baie des Cochons par des rebelles cubains en 1961 en constitue un bon exemple.

10. White Anglo-Saxon Protestant.

11. C'est le Cuban Refugee Program initié par l'administration Kennedy.

12. Sur les liens entre le succès économique et la création de la CANF, voir Vargas Llosa Alvaro (1997). 
13. Il existe un autre récit sur la fondation de la CANF. Certains auteurs soutiennent que le président Reagan aurait suggéré à quelques Cubains Américains puissants de fonder une organisation destinée à faire pression sur le pouvoir législatif et exécutif fédéral. Son but aurait été d'avoir une organisation capable de créer, à ses côtés, un consensus au sein de l'opinion publique sur la responsabilité de Fidel Castro et ses alliés sandinistes dans l'instabilité du continent américain (Haney et Vanderbush, 1999 : 341-361).

14. Cette raison explique aussi pourquoi l'attitude des Cubains de Miami est généralement décrite comme plus extrémiste que celle des Cubains du New Jersey ou du reste des États-Unis. Ces derniers ne subissent pas la pression sociale existant dans l'enclave du sud de la Floride. Néanmoins, les Cubains de Floride étant les plus nombreux et les plus engagés, ils définissent l'essentiel de la politique cubaine américaine.

15. En témoigne la réélection du maire de Hialeah (banlieue de Miami) après sa peine de prison.

16. On peut aussi citer les malversations dans l'exécution de contrats de travaux publics pour 58 millions de dollars par l'entreprise de Jorge Mas (fondateur de la CANF).

17. Ce texte renforce sensiblement l'embargo en empêchant les filiales étrangères d'entreprises américaines de commercer avec Cuba, en limitant l'envoi d'argent des familles cubaines américaines vers Cuba ou encore en interdisant à tout navire d'accoster aux États-Unis s'il s'est rendu à Cuba dans les six derniers mois.

18. La proximité des élections présidentielles et le besoin d'attirer les voix cubaines américaines n'ont pa été sans lien avec cette décision.

19. Au-delà de la quantité, c'est également le parti pris de certains organes de presse qui est à souligner dans cet épisode (Contreras, 2000 : 123-127).

20. La visite à Cuba du Pape Jean-Paul II et de Jimmy Carter durant cette période ne sont pas mentionnés à dessein. Bien que ces événements aient eu des répercussions importantes aux États-Unis, ils n'impliquaient pas directement la communauté cubaine américaine.

21. Voir à ce propos l'interview de Jorge Mas Santos (The New York Times, 2 septembre 2001 : 1.12).

22. Il a été dit précédemment que les modérés constituaient désormais la moitié de la communauté. On pourrait en déduire que cette nouvelle donne profite au Parti démocrate. Cependant, ce groupe de modérés est constitué, d'une part, de Cubains américains de seconde génération ayant des taux de participation électorale beaucoup plus bas que leurs parents conservateurs, et de l'autre, d'immigrés récemment arrivés dont tous ne possèdent pas encore la nationalité américaine.

23. La section suivante se base sur une revue de la presse anglo-saxonne des années 2000 à 2004 .

24. Son titre exact est : Assistant Secretary of State for Western Hemisphere Affairs.

25. Le résultat du travail de la commission est consigné dans un rapport disponible sur http:// www.state.gov/p/wha/rt/cuba/commission/2004/c12237.htm -Notons que Mel Martinez est devenu en 2004, le premier Cubain Américain élu au Sénat. Il représente l'État de Floride.

26. On peut citer d'autres mesures récemment prises par le président Bush dans la lutte contre le régime de Castro: le soutien à diverses ONG et à l'opposition politique à Cuba ou encore le renforcement des moyens de diffusion de TV et Radio Marti.

27. L'Institut de sondage Bendinxen \& Associates estime que les néo-arrivants, bien que représentant la moitié des Cubains de Floride, ne forment que $15 \%$ de l'électorat cubain de l'État (The New York Times, 24 juin 2004 : A1).

28. Il est difficile de chiffrer cette évolution au moment où cet article est rédigé (décembre 2004). En effet, une querelle oppose différents instituts de sondages sur l'étendue de la progression du vote hispanique en faveur du candidat Bush.

29. Nous retenons la définition de Thomas Faist selon laquelle les espaces sociaux transnationaux sont une combinaison de trois éléments: des liens, des positions dans des réseaux ou des 
organisations, et des réseaux d'organisations qui tous ont une portée à travers différents États (2000: 199-200).

30. Selon cette définition, il n'est pas nécessaire que les migrants vivent simultanément dans deux espaces pour que leurs activités aient un caractère transnational. La communauté cubaine américaine, bien qu'éprouvant des difficultés à voyager à Cuba, exerce une activité transnationale car les efforts consentis sur le territoire américain ont une influence réelle sur l’̂le dirigée par Fidel Castro. Voir Lafleur Jean-Michel (2005).

\section{RÉSUMÉS}

En retraçant les principales évolutions de la migration cubaine vers la Floride, cet article s'attache à expliquer la transformation du pouvoir économique dans l'enclave cubaine américaine de Miami en pouvoir politique. Après une période d'activisme qui voit triompher le courant conservateur, la communauté s'engage sur la voie du lobbying ethnique au début des années 1980. La cohésion et le contrôle social dans l'enclave sur lesquels s'appuie la Cuban American National Foundation illustre la force de la communauté dans sa lutte pour une politique étrangère américaine ferme à l'égard de Cuba. Toutefois, l'auteur émet l'hypothèse que l'arrivée de migrants économiques et l'ascension de la seconde génération entame la cohésion idéologique de la communauté. En révélant les dissensions nouvelles, l'auteur démontre l'émergence de pratiques transnationales dans la communauté.

\section{« ¿Bienvenidos a Miami? ». Cuban American Politics from 1959 to 2004}

Through a review of the main events that shaped Cuban migration to the United States, the article focuses on the transformation of Cuban Americans' economic power into political power. After a period of internal struggle that sees the conservative stream overcoming the other political streams, from 1980 onwards, the community becomes active in the field of ethnic lobbying. Social control and cohesion in the community are two elements that are used to explain the success of the community (and its most famous advocacy group, the Cuban American National Foundation) in promoting a harsh American foreign policy towards Cuba. The author however argues that signs of dissensions have recently appeared due the different visions brought about by recently arrived migrants and the second generation Cuban American. The article concludes by replacing those dissensions into the context of emerging transnational practices in the community.

\section{« ¿Bienvenidos a Miami? ». La política cubana americana de 1959 a 2004}

Mediante el repaso a los principales sucesos que caracterizaron la emigración cubana hacia el Estado Norteamericano de Florida, el presente artículo se aproxima al origen de la transformación del poder económico en poder político de la comunidad cubanoamericana. A partir de 1980, despues de un periodo de luchas internas que llevó al conservadurismo al frente de la comunidad, ésta comienza su actividad en el campo del lobbying étnico. Cohesión y control social son la base del éxito de esta comunidad (y de sus célebre Fundación Nacional Cubano Americana) en la promoción de una rígida política exterior norteamericana hacia Cuba. El autor, no obstante, plantea la hipótesis de las primeras disensiones internas : la segunda generación de cubanoamericanos y la llegada de nuevos inmigrantes cubanos al territorio norteamericano han traído consigo una nueva perspectiva fuente de conflicto con la primera generación. 
Finalemente, el autor reflexiona sobre los efectos de dichas disensiones en el contexto de las emergentes actividades transnacionales de la communidad.

INDEX

Index géographique : États-Unis

Mots-clés : Cubains, participation politique, politisation

\section{AUTEUR}

JEAN-MICHEL LAFLEUR

Aspirant FNRS attaché au Centre d'Études de l'Ethnicité et des Migrations de l'Institut des Sciences Humaines et Sociales, Université de Liège. Membre du réseau IMISCOE. J.M.

Lafleur@ulg.ac.be 